\title{
Phase II trial of radiotherapy after hyperbaric oxygenation with chemotherapy for high-grade gliomas
}

\author{
K Ogawa*,', Y Yoshii' ${ }^{2}$ O Inoue ${ }^{3}$, T Toita', A Saito' ${ }^{2}$, Y Kakinohana', G Adachi', S Iraha', W Tamaki', \\ K Sugimoto ${ }^{2}$, A Hyodo ${ }^{2}$ and $S$ Murayama'
}

'Department of Radiology, University of the Ryukyus School of Medicine, 207 Uehara, Nishihara-cho, Okinawa 903-021 5, Japan; ${ }^{2}$ Department of Neurosurgery, University of the Ryukyus, Okinawa, Japan; ${ }^{3}$ Department of Hyperbaric Medicine, University of the Ryukyus, Okinawa, Japan and

${ }^{4}$ Department of Radiology, Naha City Hospital, Okinawa, Japan

We conducted a phase II trial to evaluate the efficacy and toxicity of radiotherapy immediately after hyperbaric oxygenation (HBO) with chemotherapy in adults with high-grade gliomas. Patients with histologically confirmed high-grade gliomas were administered radiotherapy in daily 2 Gy fractions for 5 consecutive days per week up to a total dose of 60 Gy. Each fraction was administered immediately after $\mathrm{HBO}$ with the period of time from completion of decompression to irradiation being less than 15 min. Chemotherapy consisted of procarbazine, nimustine (ACNU) and vincristine and was administered during and after radiotherapy. $\mathrm{A}$ total of 4 I patients ( 3 I patients with glioblastoma and 10 patients with grade 3 gliomas) were enrolled. All 4 I patients were able to complete a total radiotherapy dose of $60 \mathrm{~Gy}$ immediately after $\mathrm{HBO}$ with one course of concurrent chemotherapy. Of 30 assessable patients, 17 (57\%) had an objective response including four CR and I 3 PR. The median time to progression and the median survival time in glioblastoma patients were 12.3 months and I7.3 months, respectively. On univariate analysis, histologic grade $(P=0.000 \mathrm{I})$ and Karnofsky performance status $(P=0.036)$ had a significant impact on survival, and on multivariate analysis, histologic grade alone was a significant prognostic factor for survival $(P=0.00 \mathrm{I})$. Although grade 4 leukopenia and grade 4 thrombocytopenia occurred in 10 and $7 \%$ of all patients, respectively, these were transient with no patients developing neutropenic fever or intracranial haemorrhage. No serious nonhaematological or late toxicities were seen. These results indicated that radiotherapy delivered immediately after $\mathrm{HBO}$ with chemotherapy was safe with virtually no late toxicity in patients with high-grade gliomas. Further studies are required to strictly evaluate the effectiveness of radiotherapy after $\mathrm{HBO}$ for these tumours.

British Journal of Cancer (2006) 95, 862-868. doi:I0.1038/sj.bjc.6603342 www.bjcancer.com

Published online 5 September 2006

(c) 2006 Cancer Research UK

Keywords: radiation therapy; glioma; glioblastoma; hyperbaric oxygen; chemotherapy

High-grade gliomas are relatively uncommon tumours, but cause a disproportionate number of cancer-related deaths because of their high lethality (Fine, 1994; Laperriere et al, 2002). Radiotherapy is a well established treatment for high-grade gliomas and plays an important role in the overall treatment of such patients, although it results in only a modest improvement in patient survival (Walker et al, 1978; Kristiansen et al, 1981). High-grade gliomas are generally considered to be radioresistant since a high fraction of tumour cells are hypoxic and resistant to radiotherapy as a result (Kayama et al, 1991; Rampling et al, 1994; Collingridge et al, 1999). Several reports have indicated that the median $\mathrm{pO}_{2}$ for high-grade gliomas studied under anaesthesia was approximately $5-7 \mathrm{mmHg}$ with a significant proportion of observed $\mathrm{pO}_{2}$ values being $<2.5 \mathrm{mmHg}$ (Kayama et al, 1991; Collingridge et al, 1999).

Molecular oxygen has long been recognised to be a powerful modifier of cellular radiation sensitivity. The biological effect of ionising radiation has been reported to be increased approximately

*Correspondence: Dr K Ogawa;

E-mail: kogawa@med.u-ryukyu.ac.jp

Received 12 June 2006; revised 17 July 2006; accepted 7 August 2006; published online 5 September 2006 threefold when irradiation is performed under well-oxygenated conditions compared to anoxic conditions (Gray et al, 1953). Hyperbaric oxygenation (HBO) improves the oxygen supply to hypoxic tumour cells, and offers one approach to overcome tumour cell hypoxia such that this treatment has been used in combination with radiotherapy to treat malignant tumours (Jain, 1990; Hartmann et al, 2001). In this context, HBO is using oxygen as a drug by dissolving it in the plasma and delivering it to the tissues independent of haemoglobin. In some clinical trials and recent meta-analyses, significant improvements in both local tumour control and patient survival have been seen in patients with cancers of the head and neck and uterine cervix (Henk et al, 1977; Lindegaard et al, 1996; Overgaard and Horsman, 1996). Nevertheless, the delivery of simultaneous irradiation in combination with $\mathrm{HBO}$ is complex and time-consuming with some trials noting increased side effects (Jain, 1990; Dische, 1991; Dowling et al, 1992). As a result, the regimen of HBO in combination with simultaneous radiotherapy has not been used as a standard treatment for malignant tumours.

However, recent studies suggest that the oxygen tension within tumours improves during $\mathrm{HBO}$ with the increase being maintained for minutes following cessation of HBO (Kinoshita et al, 2000, Kunugita et al, 2001; Beppu et al, 2002). Many investigators have 
reported that malignant glioma cellular metabolism is anaerobic with the tumour exhibiting a lower oxygen consumption rate to normal white matter (Ito et al, 1982; Tyler et al, 1987; Mineura et al, 1994). The $\mathrm{pO}_{2}$ of normal brain tissue has been noted to decrease quickly after $\mathrm{HBO}$ treatment in animal experiments while the $\mathrm{pO}_{2}$ in high-grade gliomas falls more slowly after decompression as a result of the lower rate of oxygen consumption and the reduced blood flow to the tumour (Jamieson and van den Brenk, 1963). Therefore, in contrast to normal brain tissue, the $p \mathrm{O}_{2}$ within the tumour may remain elevated for a substantial period of time after decompression. The resultant increase in the oxygen tension within tumour cells would be predicted to sensitise high-grade gliomas to the cytotoxic effects of irradiation (Gray et al, 1953; Hall, 1994). This hypothesis suggests that radiotherapy immediately after HBO may increase the sensitivity of hypoxic tumour cells to radiotherapy without increasing the injury to normal brain tissue. Recently, several studies have shown the feasibility of this treatment regimen with $\mathrm{HBO}$ applied prior to radiotherapy for high-grade gliomas (Kohshi et al, 1999; Beppu et al, 2003; Ogawa et al, 2003). However, there has been little information regarding the clinical efficacy and safety of this treatment strategy.

In addition to radiotherapy, chemotherapy is often administered as a peri- or post-radiation treatment for patients with high-grade gliomas. Although the role of chemotherapy remains controversial, recent meta-analyses have demonstrated an increase in patient survival for patients treated with both chemotherapy and radiotherapy as opposed to those treated with radiotherapy alone (Fine et al, 1993; Stewart, 2002). Moreover, a recent randomised trial also demonstrated that the addition of concurrent chemotherapy (temozolomide) to radiotherapy resulted in a clinically meaningful and statistically significant survival benefit for patients with newly diagnosed glioblastoma (Stupp et al, 2005). Therefore, the standard of care has now shifted from radiotherapy alone to concurrent chemo/radiotherapy for these tumours.

Based on this background, we conducted a phase II study to evaluate the efficacy and toxicity of radiotherapy after HBO together with chemotherapy in adults with high-grade gliomas.

\section{MATERIALS AND METHODS}

\section{Patient selection}

This study was performed according to the guidelines approved by the institutional review board of our institution, with written informed consent being obtained from all patients. Patients aged 18 years of age or older with a histologically confirmed supratentorial glioblastoma, anaplastic astrocytoma, anaplastic oligoastrocytoma or anaplastic oligodendroglioma according to the World Health Organization (WHO) criteria (2000) who had not received prior treatment were eligible to take part in the study. All slides were reviewed by the same neuropathologist at our institution (SA). Other eligibility criteria included the following: Karnofsky performance status (KPS) score $\geqslant 50 \%$, normal bone marrow function (haemoglobin $\geqslant 10 \mathrm{~g} \mathrm{dl}^{-1}$, white blood cell (WBC) count $\geqslant 3000 \mu \mathrm{l}^{-1}$, platelet count $\geqslant 100000 \mathrm{~mm}^{-3}$ ), normal renal function (serum creatinine $<1.2 \mathrm{mg} \mathrm{dl}^{-1}$ ), normal liver function (AST $<1.5$ times normal, bilirubin $<1.5 \mathrm{mg} \mathrm{dl}^{-1}$ ) and no evidence of cardiopulmonary disease or sinusitis.

\section{Hyperbaric oxygenation}

Hyperbaric oxygenation treatment was performed in a multiplace hyperbaric chamber according to the following schedule: approximately $18 \mathrm{~min}$ of compression with air, $30-60 \mathrm{~min}$ of $100 \%$ oxygen inhalation using an oxygen mask at 2.8. Atmospheres absolute and approximately $18 \mathrm{~min}$ of decompression with oxygen inhalation.
Following HBO, each patient was promptly moved to the treatment room and underwent radiotherapy. The period of time from completion of decompression to irradiation was consistently $<15 \mathrm{~min}$ for each treatment fraction. All patients were gowned in regulation nonflammable pyjamas and no patients received sedation for each session.

\section{Radiotherapy}

Radiotherapy began within 4 weeks of surgical resection. Each irradiation treatment was administered daily after $\mathrm{HBO}$ and was delivered with megavoltage machines of photon energies $\geqslant 4 \mathrm{MeV}$. A head-holding device that was transparent to X-rays was used in order to ensure adequate immobilisation during radiotherapy and reproducibility. The treatment volume for both the initial volume and the boost volume was based on the preoperative computed tomography (CT) or magnetic resonance imaging (MRI) scans, and CT-guided treatment planning was required. The radiotherapy schedule consisted of a total dose of $60 \mathrm{~Gy}$ prescribed at the International Commission on Units and Measurements (ICRU) reference point and administered in 30 daily fractions over a period of 6 weeks ( 5 fractions per week). For the first $40 \mathrm{~Gy}$, the treatment volume consisted of the contrast-enhancing lesions and surrounding oedema demonstrated on the CT or MRI scans with a $3 \mathrm{~cm}$ margin. After $40 \mathrm{~Gy}$, the treatment volume was reduced and included the contrast-enhancing lesion (without oedema) apparent on the preoperative CT or MRI scans with a $2.5 \mathrm{~cm}$ margin. Anticonvulsive drugs, such as phenytoin or zonisamide, were administered orally to all patients during and after radiotherapy. Corticosteroids were used perioperatively, during the early phase of radiotherapy and as necessary thereafter. The corticosteroid dose had to remain stable for at least 1 week prior to entry into the study.

\section{Chemotherapy}

Initial chemotherapy was administered concurrently with radiotherapy. One course of chemotherapy consisted of procarbazine $90 \mathrm{mg} \mathrm{m}^{-2}$ orally on days $1-14$, nimustine (ACNU) $80 \mathrm{mg} \mathrm{m}^{-2}$ intravenously on day 1 and vincristine $0.5 \mathrm{mg} \mathrm{m}^{-2}$ intravenously on days 1 and 8 . Cycles of chemotherapy were repeated at approximately 3 monthly intervals after radiotherapy up to a maximal total of four courses or until the tumour progressed or until the patient refused to receive further chemotherapy. All patients received antiemetics with granisetron and metoclopramide before ACNU administration.

\section{Patient evaluations}

The extent of surgical resection was determined from the surgical records and postoperative CT or MRI scans by the neurosurgeons (YY and SA). Gross total resection represented a complete removal of the visible tumour, partial resection involved a 5-99\% volume reduction and a biopsy sample indicated a $<5 \%$ resection. All patients underwent a complete clinical history and physical examination, preoperative and postoperative CT and/or MRI scans, complete blood count (CBC), differential white cell count, platelet count, chemistry survey, neuropsychological testing and a chest radiograph before entry into the study. CBC, differential white cell count and platelet counts were obtained every week during treatment while a chemistry survey was performed every 2 weeks during treatment. Neurological examination and contrastenhanced CT or MRI scans were obtained every 6-8 weeks during the first year. During the second year, patients in remission were evaluated with neurological examinations and contrast-enhanced CT or MRI scans at 3-month intervals. Neuropsychological assessment was conducted before radiation therapy and every 6 months thereafter or until the patient could no longer be tested. 


\section{Assessment of response and toxicity}

Assessment of response was based on postoperative CT or MRI scans that were obtained before and after radiotherapy and by neurological examination as described by Macdonald et al (1990). In brief, complete response (CR) was defined as the complete disappearance of all visible tumour, no steroid therapy and a neurologically stable or improved condition. Partial response (PR) was defined as a $\geqslant 50 \%$ reduction in the product of the perpendicular diameters of the contrast-enhancing tumour in patients on a stable or decreasing dose of steroids who were neurologically stable or improved. Progressive disease (PD) was defined as a $>25 \%$ increase in the product of the perpendicular diameters of the contrast-enhancing tumour or any new tumour seen on CT or MRI scans or neurologically worse, and the steroid dose being stable or increased. All other situations were defined as stable disease (SD). On the other hand, patients with no measurable contrast enhancing disease postoperatively were deemed to be non-assessable for response determination.

All toxicities were recorded and graded according to the common toxicity criteria of the National Cancer Institute, version 2.0. The dose of chemotherapy was decreased $33 \%$ for a nadir WBC count $1000-1500 \mu \mathrm{l}^{-1}$ or platelet count $20000-50000 \mu \mathrm{l}^{-1}$. For a nadir WBC count $<1000 \mu \mathrm{l}^{-1}$ or platelet count $<20000 \mu \mathrm{l}^{-1}$, the dose of all agents was decreased by $50 \%$. Chemotherapy was delayed if the WBC count was $<3000 \mu \mathrm{l}^{-1}$ or the platelet count $<100000 \mu \mathrm{l}^{-1}$ at the beginning of each cycle until marrow recovery had occurred. Radiotherapy was delayed if the WBC count was $<1000 \mu \mathrm{l}^{-1}$ or the platelet count $<20000 \mu \mathrm{l}^{-1}$ until marrow recovery had occurred. Chemotherapy was delayed if the AST level was elevated or if the direct bilirubin level was less than three times normal, until values fell to below twice the upper limit of normal. Chemotherapy was then restarted at $50 \%$ of the initial dose.

\section{Statistical analysis}

Overall survival and progression-free survival rates were calculated actuarially according to the Kaplan-Meier method (Kaplan and Meier, 1958) and were measured from the day of surgical resection. Differences between groups were estimated using the log rank test (Mantel, 1966). Multivariate analysis was performed using the Cox regression model (Cox, 1972). A probability level of 0.05 was chosen for statistical significance. Statistical analysis was performed using the SPSS software package (version 11.0; SPSS Inc., Chicago, IL, USA).

\section{RESULTS}

\section{Patient characteristics}

Forty-one adults with newly diagnosed supratentorial high-grade gliomas were enrolled onto this trial between January 2000 and December 2003. The patient characteristics are detailed in Table 1. All patients were followed through December 2005 or until they died, and were evaluated for efficacy and toxicity of this treatment. The median follow-up time in the surviving patients was 57.1 months (range 28.1-70.6 months).

\section{Treatment delivered}

All 41 patients completed a total dose of $60 \mathrm{~Gy}$ radiotherapy immediately after $\mathrm{HBO}$ with one course of concurrent chemotherapy. Thirty-three of 41 patients $(80 \%)$ received further courses of chemotherapy after radiotherapy. The total courses of chemotherapy administered were four courses in 10 patients, three courses in six patients, two courses in 17 patients, and one course in eight patients.
Table I Patient characteristics

\begin{tabular}{|c|c|}
\hline Characteristic & No. of patients \\
\hline Total number of patients & 41 \\
\hline \multicolumn{2}{|l|}{ Gender } \\
\hline Male & 24 \\
\hline Female & 17 \\
\hline \multicolumn{2}{|l|}{ Age (years) } \\
\hline Median & 57 \\
\hline Range & $22-73$ \\
\hline \multicolumn{2}{|l|}{ KPS (\%) } \\
\hline Median & 80 \\
\hline Range & $50-100$ \\
\hline \multicolumn{2}{|l|}{ Histologic grade } \\
\hline 3 & 10 \\
\hline 4 & 31 \\
\hline \multicolumn{2}{|l|}{ Tumour location } \\
\hline Frontal & 15 \\
\hline Other & 26 \\
\hline \multicolumn{2}{|l|}{ Tumour size } \\
\hline$\leqslant 4 \mathrm{~cm}$ & 10 \\
\hline$>4 \mathrm{~cm}$ & 31 \\
\hline \multicolumn{2}{|l|}{ Mental status } \\
\hline Normal & 35 \\
\hline Abnormal & 6 \\
\hline \multicolumn{2}{|l|}{ Radiation from symptom } \\
\hline$\leqslant 3$ months & 22 \\
\hline$>3$ months & 19 \\
\hline \multicolumn{2}{|l|}{ Neurologic function } \\
\hline Work & 21 \\
\hline Other & 20 \\
\hline \multicolumn{2}{|l|}{ Histology } \\
\hline GM & 31 \\
\hline AA & 4 \\
\hline $\mathrm{AO}$ & 6 \\
\hline \multicolumn{2}{|l|}{ Extent of resection } \\
\hline Gross total & 11 \\
\hline Partial & 24 \\
\hline Biopsy & 6 \\
\hline
\end{tabular}

\section{Response, survival and prognostic factors}

Eleven patients had undergone a gross total resection and had no evaluable tumour at the initiation of protocol therapy. Therefore, 30 of 41 patients could be evaluated for response within 1 month after the completion of radiotherapy (glioblastoma: 22 patients, grade-3 gliomas: eight patients). Of these 30 patients, 17 (57\%) had an objective response including four CR (13\%) and 13 PR $(43 \%)$. Twelve patients (40\%) had SD and one patient experienced PD.

At the time of this analysis, 33 patients died (30 patients with glioblastoma and three patients with grade 3 tumours) and two patients with grade 3 tumours were alive with evidence of disease progression (follow-up, 36.9 and 28.1 months, respectively). The remaining six patients (one patient with glioblastoma and five patients with grade 3 tumours) had no evidence of tumour recurrence or disease progression (median follow-up, 68.2 months; range, 34.6-70.6 months). The median time to progression and the 
median survival time in glioblastoma patients were 12.3 months and 17.3 months, respectively. The 2-year actuarial progressionfree survival and the 2-year actuarial overall survival rates in glioblastoma patients were 10 and $23 \%$, respectively.

Table 2 indicates the results of univariate and multivariate analyses of potential prognostic factors on survival. On univariate analysis, histologic grade $(P=0.0001)$ and Karnofsky performance status $(P=0.036)$ had a significant impact on survival, and on multivariate analysis, histologic grade alone was a significant prognostic factor for survival $(P=0.001)$.

\section{Toxicity}

During HBO treatment, seven of 41 (17\%) patients suffered middle ear barotrauma requiring tympanostomy with tube placement. Five of $41(12 \%)$ patients had complaints of nausea requiring metoclopramide before each $\mathrm{HBO}$ treatment. No patients suffered convulsions during or after HBO.

The major acute toxic effects of chemotherapy ( $\geqslant$ grade 3 ) represent the most severe toxicity associated with the study treatment for each patient (Table 3). The percentage of grade 3-4 leukopenia, anaemia and thrombocytopenia were 44,5 and $48 \%$, respectively, with three patients $(7 \%)$ requiring platelet transfusions and one patient (2\%) requiring blood cell transfusions. Although grade 4 leukopenia and grade 4 thrombocytopenia occurred in 10 and $7 \%$ of all patients, respectively, these were transient with no patients developing a neutropenic fever or intracranial haemorrhage. Grade 3 nausea occurred in three patients (7\%). Three patients (7\%) developed grade 3 liver dysfunction and were treated conservatively. No other grade 3 or more severe nonhaematological toxicities were observed in the remaining patients. No severe late toxicities, such as intracranial haemorrhage and mental deterioration, were evident in the surviving patients at the time of analysis.

All patients exhibited alopecia within the treatment field. Regrowth of hair occurred over a time period of 4-8 months from the end of irradiation. Localised scalp erythema was seen in all patients although no patient experienced moist desquamation.

\section{Comparison of survival according to RPA criteria}

We analysed our patients according to the recursive partitioning analysis (RPA) prognostic factors (Curren et al, 1993), which are based on a large Radiation Therapy Oncology Group (RTOG) database of patients with high-grade gliomas (Scott et al, 1998). Each RPA III, IV and V group in the current study had longer median survival time and higher 2-year survival than those of RTOG 90-06 results reported from Scott et al (Table 4).

\section{DISCUSSION}

In recent years, radiotherapy immediately after $\mathrm{HBO}$ has been emerging as an attractive approach for overcoming hypoxia in cancer treatment (Al-Waili et al, 2005; Bennett et al, 2005; Mayer et al, 2005). Several experimental studies have indicated that the elevation in oxygen tension in the tumour is preserved for some time following HBO treatment, thereby allowing the administration of radiotherapy with an improved tumour/normal tissue oxygenation ratio (Kinoshita et al, 2000; Kunugita et al, 2001; Beppu et al, 2002). Using noninvasive MRI, Kinoshita et al (2000) demonstrated that the signal change related to the oxygen tension in SCCVII tumours decreased gradually but fell rapidly in muscle after HBO. Beppu et al (2002) conducted a direct stereotactic measurement of $\mathrm{pO}_{2}$ in glioblastoma tissue of patients under various conditions. The $\mathrm{pO}_{2}$ levels were significantly increased in both peritumoral and intratumoral tissues after $\mathrm{HBO}$ with a high $p \mathrm{O}_{2}$ level being maintained until $15 \mathrm{~min}$ after $\mathrm{HBO}$ in both regions. Moreover, performing radiotherapy immediately after HBO had a significant effect in experimental studies. Kunugita et al (2001) examined the effect of radiotherapy after HBO in SCCVII tumours (radiobiological hypoxic fraction: approximately 10\%) subcutaneously transplanted into $\mathrm{C} 3 \mathrm{H} / \mathrm{He}$ mice using a growth delay assay. They noted a significant SCCVII tumour growth delay in the treated animals within $30 \mathrm{~min}$ after $\mathrm{HBO}$ with the tumour growth delay time being 1.61 times longer than that following radiotherapy alone. Moreover, oxygenation using $\mathrm{HBO}$ also enhanced the sensitivity to chemotherapy, because the hypoxic conditions prevalent in the tissue compromised the chemotherapeutic potential of almost all agents (Rampling et al, 1994; Al-Waili et al, 2005).

The current study suggested that radiotherapy administered immediately after HBO with chemotherapy may be promising for high-grade gliomas. Moreover, the administration of radiotherapy after HBO enabled the application of conventional fractionation of radiotherapy and the combination of modern radiotherapy

Table 3 Major toxicities $(n=4 I)$

\begin{tabular}{|c|c|c|c|c|}
\hline & \multicolumn{2}{|c|}{ Grade 3} & \multicolumn{2}{|c|}{ Grade 4} \\
\hline & No. & $\%$ & No. & $\%$ \\
\hline Leukocytes & 14 & 34 & 4 & 10 \\
\hline Haemoglobin & 2 & 5 & 0 & 0 \\
\hline Platelets & 17 & 41 & 3 & 7 \\
\hline Nausea & 3 & 7 & 0 & 0 \\
\hline Hepatic toxicity & 3 & 7 & 0 & 0 \\
\hline
\end{tabular}

Table 2 Univariate and multivariate analysis of various potential prognostic factors in patients with high-grade gliomas

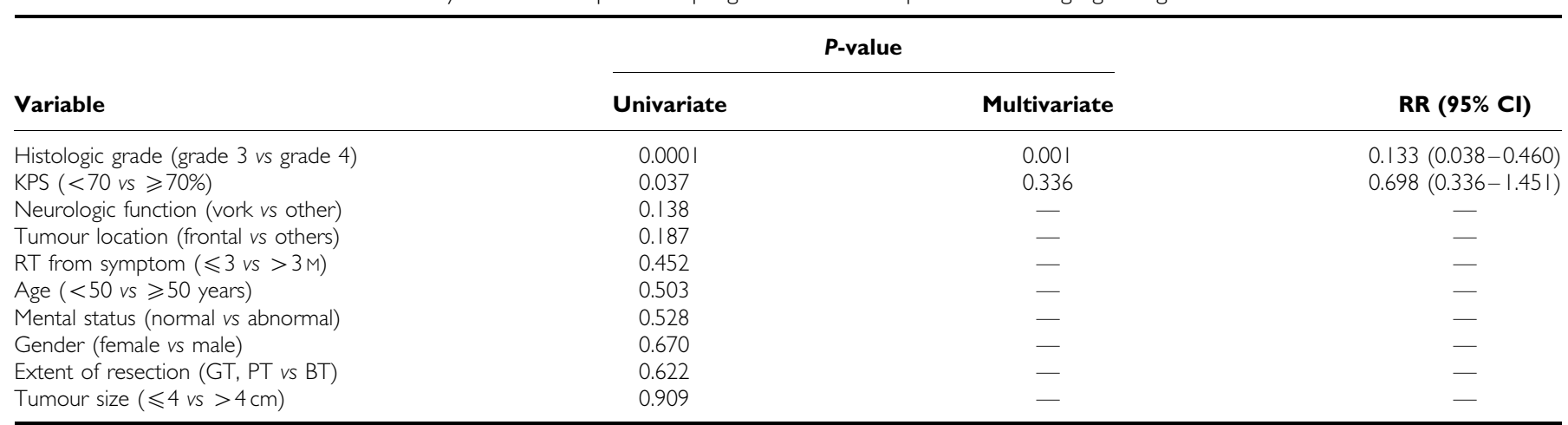

$\mathrm{BT}=$ biopsy; $\mathrm{Cl}=$ confidence intervals; $\mathrm{GT}=$ gross total resection; $\mathrm{KPS}=$ Karnofsky performance status; $\mathrm{M}=$ months; $\mathrm{PT}=$ partial resection; $\mathrm{RR}=$ relative risk. 
Table 4 Comparison of survival according to recursive partitioning analysis criteria

\begin{tabular}{|c|c|c|c|c|c|c|}
\hline & \multicolumn{3}{|c|}{ Current study } & \multicolumn{3}{|c|}{ RTOG $90-06^{a}$} \\
\hline & No. of patients ${ }^{b}$ & Median survival (months) & 2-year survival (\%) & No. of patients & Median survival (months) & 2-year survival (\%) \\
\hline $\begin{array}{l}\text { IV } \\
95 \% \mathrm{Cl}\end{array}$ & 8 & $\begin{array}{c}20.4 \\
15.1-25.7\end{array}$ & $\begin{array}{c}38 \\
4-72\end{array}$ & 240 & $\begin{array}{c}11.5 \\
10.8-12.7\end{array}$ & $\begin{array}{c}17 \\
11-22\end{array}$ \\
\hline $\begin{array}{l}V \\
95 \% \mathrm{Cl}\end{array}$ & 15 & $\begin{array}{c}12.6 \\
9.9-18.5\end{array}$ & $\begin{array}{c}20 \\
0-40\end{array}$ & 150 & $\begin{array}{c}7.4 \\
6.2-9.1\end{array}$ & $\begin{array}{c}8 \\
3-12\end{array}$ \\
\hline
\end{tabular}

techniques including patient fixation and three-dimensional conformal therapy. Several reports have also indicated the antitumour activity of irradiation immediately after $\mathrm{HBO}$ in conventionally fractionated irradiation (Kohshi et al, 1999; Beppu et al, 2003). Kohshi et al (1999) applied radiotherapy after HBO to high-grade glioma patients with residual disease. A total dose of $50-71 \mathrm{~Gy}$ in 20-30 fractions was administered, and 11 of 15 patients $(73 \%)$ treated with radiotherapy immediately after HBO exhibited $>50 \%$ tumour reduction. The median survivals in patients with and without HBO were 24 and 12 months, respectively, and were significantly different $(P<0.05)$. Beppu et al (2003) applied radiotherapy after HBO with ACNU and interferon-beta for high-grade gliomas and $50 \%$ of glioblastoma patients exhibited $>50 \%$ tumour reduction. The current study also indicated antitumour activity of conventionally fractionated radiotherapy delivered immediately after $\mathrm{HBO}$ with a total dose of $60 \mathrm{~Gy}$ in 30 fractions. In the 30 patients in whom it was possible to evaluate the therapeutic response (glioblastoma: 22 patients, grade 3 gliomas: eight patients), 17 (57\%) had an objective response including four CR (17\%) and 13 PR (43\%). The median survival time has been reported to be 11-15 months in several phase studies for glioblastoma (Lassen et al, 1999; Choi et al, 2002; Wick et al, 2002; Grossman et al, 2003), and was 17.3 months in the current study. When using RPA analysis criteria, we found that the median survival times and 2-year survival rates of RPA III, IV and $\mathrm{V}$ classes in the current study compared favourably with patients in the RTOG databases who were treated in a randomised trial in the early 1990s (Table 4).

However, these favourable results demonstrated in the current study should be interpreted with caution. First, the patient characteristics were generally favourable with $25 \%$ of patients undergoing gross total resection, and $25 \%$ of patients having grade 3 gliomas. The median age of 57 was relatively young and the median KPS of 80 indicated a group with good performance status. Therefore, one might expect the outcome in this group to be better than the average described in the literature for glioblastoma. Second, there is an important difference between the current study and other previous reports (mostly using adjuvant chemotherapy) as patients have received concurrent chemotherapy. Comparisons of the recent results with patients receiving concurrent temozolomide in the Stupp trial (Stupp et al, 2005) indicate that the 2-year survival rates for glioblastoma are much the same: $23 \%$ in the current study and $26.5 \%$ in the Stupp trial. Therefore, it is necessary to strictly evaluate the true effectiveness of radiotherapy after HBO for these tumours in further studies.

The current study also indicated that the administration of radiotherapy immediately after $\mathrm{HBO}$ was a safe and practical procedure. With the routine use of anticonvulsive drugs and tympanostomy with tube placement in case of middle ear barotrauma, all 41 patients were able to complete a total dose of $60 \mathrm{~Gy}$ radiotherapy with conventional fractionation delivered immediately after HBO. With regard to chemotherapy, all 41 patients could receive one course of concurrent chemotherapy, and 33 of $41(80 \%)$ patients received further chemotherapies. Whereas the spectrum of the nonhaematological toxicity was unremarkable, we observed frequent haematological toxicity with grade 3 and 4 leukopenia and thrombocytopenia (48\% of all patients). One of the reasons may be the concurrent administration of chemotherapy and radiotherapy in this protocol (Kleinberg et al, 1999). However, the incidence of grade 4 haematological toxicity was less common and was transient. No patients exhibited neutropenic fever or intracranial haemorrhage and no serious late toxicity was evident at the time of this analysis. Several authors have also used a multidrug chemotherapy regimen containing ACNU, and they also found that grade 3-4 haematological toxicity was frequent, but of short duration with very few treatment-related deaths (Choi et al, 2002; Weller et al, 2003). These results indicated that the administration of radiotherapy immediately after HBO with chemotherapy was safe and practical with virtually no late toxicity for high-grade gliomas.

Regarding prognostic factors, many studies have reported that age, KPS, tumour size, histologic grade and the extent of surgical resection significantly affect the overall survival for high-grade gliomas (Laperriere et al, 2002; Buckner, 2003). However, the current study found no significant differences in overall survival with respect to age, KPS and extent of surgical resection on multivariate analysis, and only histologic grade was a significant prognostic factor for survival. The lack of any significant differences on survival according to age, KPS and extent of surgical resection may be the result of the small number of patients in the current study. Another possible reason, however, may be the improved radiosensitivity by $\mathrm{HBO}$ to large residual tumours as well as small residual tumours. A close association may exist between KPS, tumour size, and the extent of surgical resection because the residual tumour size determined by the operation type sometimes affects KPS (Beppu et al, 2003). Improvement in the radiosensitivity of large residual tumours may contribute to an increased response rate and overall survival for patients with low KPS and/or large residual tumours. Beppu et al (2003) also found no significant differences in the response rates with regard to age, KPS, and extent of surgical resection for high-grade gliomas treated with radiotherapy immediately after HBO. They concluded that radiotherapy after $\mathrm{HBO}$ could be applied to patients with poor prognostic factors and resulted in tumour response identical to patients with good prognostic factors. Further studies are required to determine which high-grade glioma patients might effectively benefit from radiotherapy delivered immediately after HBO for high-grade glioma patients. 
In conclusion, performing radiotherapy immediately after HBO with chemotherapy was safe with virtually no late toxicity for high-grade gliomas. This treatment strategy may be promising and merits further investigation. Further prospective randomised trials are also warranted to accurately determine whether the delivery of radiotherapy immediately after HBO could be beneficial for patients with high-grade gliomas.

\section{REFERENCES}

Al-Waili NS, Butler GJ, Beale J, Hamilton RW, Lee BY, Lucas P (2005) Hyperbaric oxygen and malignancies: a potential role in radiotherapy, chemotherapy, tumor surgery and phototherapy. Med Sci Monit 11: RA279 - RA289

Bennett M, Feldmeier J, Smee R, Milross C, Bennett M (2005) Hyperbaric oxygenation for tumour sensitization to radiotherapy. Cochrane Database Syst Rev 19: CD005007

Beppu T, Kamada K, Nakamura R, Oikawa H, Takeda M, Fukuda T, Aradi H, Ogasawara K, Ogawa A (2003) A phase II study of radiotherapy after hyperbaric oxygenation combined with interferon-beta and nimustine hydrochloride to treat supratentorial malignant gliomas. J Neurooncol 61: $161-170$

Beppu T, Kamada K, Yoshida Y, Arai H, Ogasawara K, Ogawa A (2002) Changes of oxygen pressure in glioblastoma tissue under various conditions. J Neurooncol 58: $47-52$

Buckner JC (2003) Factors influencing survival in high-grade gliomas. Semin Oncol 30(6 Suppl 19): 10-14

Choi IS, Lee SH, Kim TY, Bang JS, Paek SH, Kim S, Kim IH, Heo DS, Bang YJ, Kim DG, Jung HW, Kim NY (2002) Phase II study of chemotherapy with ACNU plus cisplatin followed by cranial irradiation in patients with newlydiagnosed glioblastoma multiforme. J Neurooncol 60: 171-176

Collingridge DR, Piepmeier JM, Rockwell S, Knisely JP (1999) Polarographic measurements of oxygen tension in human glioma and surrounding peritumoral brain tissue. Radiother Oncol 53: 127-131

Cox DR (1972) Regression models and life tables. J R Stat Soc 34: 187-220

Curren Jr WJ, Scott CB, Horton J, Nelson JS, Weinstein AS, Fishbach AJ, Chang CH, Rotman M, Asbell SO, Krisch RE (1993) Recursive partitioning analysis of prognostic factors in three Radiation Therapy Oncology Group malignant glioma trials. J Natl Cancer Inst 85: 704-710

Dische S (1991) What have we learnt from hyperbaric oxygen? Radiother Oncol 20(Suppl 1): $71-74$

Dowling S, Fischer JJ, Rockwell S (1992) Fluosol and hyperbaric oxygen as an adjunct to radiation therapy in the treatment of malignant gliomas: a pilot study. Biomater Artif Cells Immobilizat Biotechnol 20: 903-905

Fine HA (1994) The basis for current treatment recommendations for malignant gliomas. J Neurooncol 20: $111-120$

Fine HA, Dear KB, Loeffler JS, Black PM, Canellos GP (1993) Meta-analysis of radiation therapy with and without adjuvant chemotherapy for malignant gliomas in adults. Cancer 71: 2585-2597

Gray LH, Conger AD, Ebert M, Hornsey S, Scott OC (1953) The concentration of oxygen dissolved in tissues at the time of irradiation as a factor in radiotherapy. $\mathrm{Br} J$ Radiol 26: 638-648

Grossman SA, O’Neill A, Grunnet M, Mehta M, Pearlman JL, Wagner H, Gilbert M, Newton HB, Hellman R (2003) Phase III study comparing three cycles of infusional carmustine and cisplatin followed by radiation therapy with radiation therapy and concurrent carmustine in patients with newly diagnosed supratentorial glioblastoma multiforme: Eastern Cooperative Oncology Group Trial 2394. J Clin Oncol 21: 1485-1491

Hall EJ (1994) Radiobiology for the Radiologist, 4th ed Lippincott: Philadelphia, pp. $408-417$

Hartmann KA, van der Kleij AJ, Carl UM, Hulshof MC, Willers R, Sminia P (2001) Effects of hyperbaric oxygen and normobaric carbogenon the radiation response of the rat rhabdomyosarcoma $\mathrm{R} 1 \mathrm{H}$. Int J Radiat Oncol Biol Phys 51: $1037-1044$

Henk JM, Kunkler PB, Smith CW (1977) Radiotherapy and hyperbaric oxygen in head and neck cancer. Final report of first controlled clinical trial. Lancet 2: $101-103$

Ito M, Lammertsma AA, Wise RJ, Bernardi S, Frackowiak RS, Heather JD, McKenzie CG, Thomas DG, Jones T (1982) Measurement of regional cerebral blood flow and oxygen utilization in patients with cerebral tumors using ${ }^{15} \mathrm{O}$ and positron emission tomography: analytical techniques and preliminary results. Neuroradiology 23: 63-74

Jain KK (1990) Textbook of Hyperbaric Medicine. Hogrefe \& Huber Publishers: Toronto, pp. 408-417
Jamieson D, van den Brenk HAS (1963) Measurement of oxygen tensions in cerebral tissues of rats exposed to high pressures of oxygen. J Appl Physiol 18: $869-876$

Kaplan EL, Meier P (1958) Nonparametric estimation from incomplete observations. J Am Stat Assoc 53: $457-481$

Kayama T, Yoshimoto T, Fujimoto S, Sakurai Y (1991) Intratumoral oxygen pressure in malignant brain tumor. J Neurosurg 74: 55-59

Kinoshita Y, Kohshi K, Kunugita N, Tosaki T, Yokota A (2000) Preservation of tumour oxygen after hyperbaric oxygenation monitored by magnetic resonance imaging. $\mathrm{Br} J$ Cancer 82: 88-92

Kleinberg L, Grossman SA, Piantadosi S, Zeltzman M, Wharam M (1999) The effects of sequential $v s$ concurrent chemotherapy and radiotherapy on survival and toxicity in patients with newly diagnosed high-grade astrocytoma. Int J Radiat Oncol Biol Phys 44: 535-543

Kohshi K, Kinoshita Y, Imada H, Kunugita N, Abe H, Terashima H, Tokui $\mathrm{N}$, Uemura S (1999) Effects of radiotherapy after hyperbaric oxygenation on malignant gliomas. Br J Cancer 80: 236-241

Kristiansen K, Hagen S, Kollevold T, Torvik A, Holme I, Nesbakken R, Hatlevoll R, Lindgren M, Brun A, Lindgren S, Notter G, Andersen AP, Elgen K (1981) Combined modality therapy of operated astrocytomas grade III and IV. Confirmation of the value of postoperative irradiation and lack of potentiation of bleomycin on survival time: a prospective multicenter trial of the Scandinavian glioblastoma study group. Cancer 47: $649-652$

Kunugita N, Kohshi K, Kinoshita Y, Katoh T, Abe H, Tosaki T, Kawamoto $\mathrm{K}$, Norimura T (2001) Radiotherapy after hyperbaric oxygenation improves radioresponse in experimental tumor models. Cancer Lett 164: $149-154$

Laperriere N, Zuraw L, Cairncross G (2002) Radiotherapy for newly diagnosed malignant glioma in adults: a systematic review. Radiother Oncol 64: $259-273$

Lassen U, Kristjansen PE, Wagner A, Kosteljanetz M, Poulsen HS (1999) Treatment of newly diagnosed glioblastoma multiforme with carmustine, cisplatin and etoposide followed by radiotherapy. A phase II study. J Neurooncol 43: $161-166$

Lindegaard JC, Overgaard J, Bentzen SM, Pedersen D (1996) Is there a radiobiologic basis for improving the treatment of advanced stage cervical cancer? J Natl Cancer Inst Monogr 21: 105-112

Macdonald DR, Cascino TL, Schold Jr SC, Cairncross JG. (1990) Response criteria for phase II studies of supratentorial malignant glioma. J Clin Oncol 21: $3547-3549$

Mantel N (1966) Evaluation of survival data and two new rank order statistics arising in its consideration. Cancer Chemother Rep 50: 163-170 Mayer R, Hamilton-Farrell MR, van der Kleij AJ, Schmutz J, Granstrom G, Sicko Z, Melamed Y, Carl UM, Hartmann KA, Jansen EC, Ditri L, Sminia $\mathrm{P}$ (2005) Hyperbaric oxygen and radiotherapy. Strahlenther Onkol 181: $113-123$

Mineura K, Sasajima T, Kowada M, Ogawa T, Hatazawa J, Shishido F, Uemura K (1994) Perfusion and metabolism in predicting the survival of patients with cerebral gliomas. Cancer 73: 2386-2394

Ogawa K, Yoshii Y, Inoue O, Toita T, Saito A, Kakinohana Y, Adachi G, Ishikawa Y, Kin S, Murayama S (2003) Prospective trial of radiotherapy after hyperbaric oxygenation with chemotherapy for high-grade gliomas. Radiother Oncol 67: 63-67

Overgaard J, Horsman MR (1996) Modification of hypoxia-induced radioresistance in tumors by the use of oxygen and sentitizers. Semin Radiat Oncol 6: 10-21

Rampling R, Cruickshank G, Lewis AD, Fitzsimmons SA, Workman P (1994) Direct measurement of $\mathrm{pO}_{2}$ distribution and bioreductive enzymes in human malignant brain tumors. Int $\mathrm{J}$ Radiat Oncol Biol Phys 29: $427-431$

Scott CB, Scarantino C, Urtasun R, Movsas B, Jones CU, Simpson JR, Fischbach AJ, Curran Jr WJ (1998) Validation and predictive power of Radiation Therapy Oncology Group (RTOG) recursive partitioning 
analysis classes for malignant glioma patients: a report using RTOG 9006. Int J Radiat Oncol Biol Phys 40: $51-55$

Stewart LA (2002) Chemotherapy in adult high-grade glioma: a systemic review and meta-analysis of individual patient data from 12 randomized trials. Lancet 359: 1011-1018

Stupp R, Mason W, van der Bent MJ, Weller M, Fisher B, Taphoorn MJB, Belanger $\mathrm{K}$, Brandes AA, Marosi C, Bogdahn U, Curshmann J, Janzer RC, Ludwin SK, Gorlia T, Allgeier A, Lacombe D, Cairncross G, Eisenhauer E, Mirimanoff RO (2005) Radiotherapy plus concomitant and adjuvant temozolomide for glioblastoma. $N$ Engl J Med 352: $987-996$

Tyler JL, Diksic M, Villemure JG, Evans AC, Meyer E, Yamanoto YL, Feindel W (1987) Metabolic and hemodynamic evaluation of gliomas using positron emission tomography. J Nucl Med 33: 1123-1133
Walker MD, Alexander Jr E, Hunt WE, MacCarty CS, Mahaley Jr MS, Mealey Jr J, Norrell HA, Owens G, Ransohoff J, Wilson CB, Gehan EA, Strike TA (1978) Evaluation of BCNU and/or radiotherapy in the treatment of anaplastic gliomas: a cooperative clinical trial. J Neurosurg 49: $333-343$

Weller M, Muller B, Koch R, Bamberg M, Krauseneck P (2003) NeuroOncology Working Group 01 trial of nimustine plus tenitoside $v s$ nimustine plus cytarabine chemotherapy in addition to involved-field radiotherapy in the first line treatment of malignant glioma. J Clin Oncol 21: $3276-3284$

Wick W, Hermisson M, Kortmann RD, Kuker WM, Duffner F, Dichgans J, Bamberg M, Weller M (2002) Neoadjuvant gemcitabine/treosulfan chemotherapy for newly diagnosed glioblastoma: a phase II study. J Neurooncol 59: 151 - 155 